\title{
REFRAMING THE DESIGN PROCESS: INTEGRATING GOALS, METHODS AND MANIFESTATION INTO THE CO- EVOLUTION MODEL
}

\author{
Storm, Rosa; van Maanen, Jeffrey; Gonçalves, Milene \\ Delft University of Technology
}

\begin{abstract}
In their early years of education, design students may experience difficulties in reframing design problems. Since reframing is linked to creativity, this may be problematic. While there are some models available to describe the reframing process, it is yet unclear how they are supporting design students. This study concerned the development and test of a framing model based on co-evolution transitions, through a two-part study: interviews with expert designers and workshops followed by group interviews with novices. The resulting model offers a way of thinking and a way of working, based on the fluidity of the design process. This study yielded two major insights. Firstly, students tend to perceive the problem space to be fixed once they defined it, even if they discovered disparate information along the way. Secondly, the developed model provides students with guidance and confidence in dealing with complex problems. Our results have a considerable impact on design education, as it is important to reinforce to design students that both the problem and solution understanding are fluid, and this model provides initial steps to help designers structuring their process.
\end{abstract}

Keywords: Design methodology, Design education, Creativity, Co-Evolution, Human behaviour in design

Contact:

Storm, Rosa Maria Roelien

Delft University of Technology

Industrial Design Engineering

The Netherlands

r.m.r.storm@student.tudelft.nl

Cite this article: Storm, R., van Maanen, J., Gonçalves, M. (2019) 'Reframing the Design Process: Integrating Goals, Methods and Manifestation into the Co-Evolution Model', in Proceedings of the 22nd International Conference on Engineering Design (ICED19), Delft, The Netherlands, 5-8 August 2019. DOI:10.1017/dsi.2019.39 


\section{INTRODUCTION}

In their early years of design education, it is common to observe that many design students experience difficulties in defining and reframing the design problem (Cross, 2004). Framing is a term commonly used within design literature for the creation of a (novel) standpoint from which a problematic situation can be tackled (Dorst, 2011). The term framing is commonly used within design literature since Schön (1983). Framing is explained by Schön (1988, p. 182) as follows: "In order to formulate a design problem to be solved, the designer must frame a problematic design situation: set its boundaries, select particular things and relations for attention, and impose on the situation a coherence that guides subsequent moves". Sometimes, during the design process, a new frame is necessary, especially when a surprising or unexpected event occurs, which does not fit the current understanding. In these situations, one may say that surprises, which can come as new information, activities or interactions (Cash and Gonçalves, 2017) can trigger reframing (Stompff, Smulders, and Henze, 2016). A growing number of researchers have explored framing in relation to the design process and creativity. Christiaans (1992, p. 145) reported on his study on design students that "a relationship was found between the time spent reflecting on the problem in the first part of the design process and the creativity of the result". Framing the design problem is therefore a key aspect of creativity, considered to be more difficult for novices than for expert designers (Kim \& Ryu, 2014). This mechanism was also described by Akin \& Akin (1996), who found that setting frames of reference and, more importantly, breaking them are key ingredients of Sudden Mental Insights, or Aha!-moments. In addition, Cross (1997) characterised creative designing as oscillating between sub-problems and subsolutions, and furthermore defines 'a creative leap' as the recognition of a concept that bridges the problem and solution in a way that satisfies the problem. Dorst \& Cross (2001) researched the design process of nine individual designers and found that they simultaneously work on the problem and the solution while designing. Their findings underpinned the earlier defined co-evolution model (Maher \& Poon, 1996) into the field of design. Designers, while working on a design problem, move between the 'problem space', where the problem is formulated, defined, and understood, and the 'solution space', where the designer comes up with solutions for the problem. This process is called co-evolution. Wiltschnig et al. (2013) further demonstrated the presence of co-evolution episodes in design teams. They showed that the co-evolution process is very important for generating solutions since the most solution attempts by the researched design team (84\% of attempts) happened within co-evolution episodes. This shows that solution generation is closely related to co-evolution episodes, and thus a well-framed problem space.

For design teams, framing the problem space can be difficult (Hey et al., 2007). This is mostly due to team members arriving at the design process with different frames. These frames are shaped by previous experiences and beliefs. If frames are not aligned, i.e. the team problem space is not framed collaboratively, it can lead to conflicts and team members working in separate directions.

In summary, past studies have established that co-evolution episodes occur in the design processes of individuals as well as those of teams. We also know that the definition of the problem space has a significant impact on the development of the solution space, i.e. the outcome of the design process. Furthermore, teams also have the additional cognitive task of having to reach a shared understanding among team members' individual frames, in order to reframe the problem. On the other hand, they might experience difficulties reframing too, especially novice designers. Without having their frames challenged, individual design students might struggle with stepping away from the given design brief, which hampers reframing. Despite being generally acknowledged that novices are less effective at reframing compared to experts (e.g., Almendra \& Christiaans, 2011; Kim \& Ryu, 2014), little is still known about how to train and support design students' framing practice. This paper will examine this issue by addressing two main questions. First, we aim to investigate how we can support designers in reframing by developing a model, supported by design tools. Secondly, we will critically examine the reframing model we developed, by testing its effects on the design process of design students. The remaining parts of the paper are organised in the following manner: After an overview of relevant literature, we present both parts of the study, followed by their results and discussion. Finally, we present a refined version of our reframing model, based on our findings and the co-evolution model, in relation to implications for design education and practice. 


\section{LITERATURE REVIEW}

There are a number of models and methods that describe the reframing process (e.g., Dorst, 2015; Stompff et al., 2016). As a starting point, it is relevant to define what is meant with models and methods within this paper, since the approaches here described fall in either one of those categories. Saunders (2007, p. 595) defines methods as "the techniques and procedures used to obtain and analyse research data", which can be translated to sets of steps to follow in order to get to meaningful results. Models, on the other hand, represent certain aspects and their relations, aiding in understanding of how a system works (Suppes, 1960).

The Delft Design Guide (van Boeijen et al., 2013) provides a concise overview of several existing methods and models in design. We will focus now on a number of these that take problem framing and/or reframing moderately into account. Three of these methods are Problem definition, List of requirements and Search areas. These methods either assume that the problem space can be completely defined within a few iterations (Problem definition and List of requirements) or focus only on a specific phase in the design process (Search Areas).

In addition to these methods, van Boeijen et al. (2013) describe several models that cover the complete design process, including the definition of the problem space. Some relevant models are the Basic design cycle, the Product innovation process $1 \& 2$, Creative problem solving and Brand driven innovation. While all of these models incorporate methods that are very useful for the definition of the problem space, they implicitly seem to consider the problem space as rigid. Once it is defined, the designer is guided towards idea generation and development. Three of the models, the Basic design cycle, the Product innovation process 2 and Brand driven innovation, do look back at the problem space. However, they only do it at the end of the complete design cycle.

Outside the aforementioned models and methods, other authors developed approaches that address reframing. Dorst (2015) introduced a nine-step model to create frames, where the first six steps are used to reframe the current problem. It is an elaborate process with a variety of steps in the form of exercises, but mainly focused on reframing the problem space. Therefore, it might be missing out on the other parts of the design process. Benammar (2012) suggests a method that reframes beliefs. The method splits a core belief into supporting ones, which subsequently are transformed into their opposites. With these opposites a new core belief is created. The process is short and gives a quick reframing opportunity, but it loses the connection between the problem and solution space. It only focuses on either one of them at each point. Considering the relevance of the aforementioned models and methods, but their lack of clear steps, in design education internationally, it is yet unclear how are they supporting design students in reframing. Thus, there is a need for an implementable approach to support design students, that acknowledges the iterative process of the problem space, which regularly refers back to the problem space and (re)frames it when necessary.

\section{SET UP OF THE TWO-PARTS STUDY - PART 1}

As previously mentioned, reframing the problem space is considered to be important for the outcome of a design process (e.g., Dorst \& Cross, 2001; Christiaans, 1992). However, there is a lack of approaches that continuously stimulate and guide designers to reframe. Especially in design education, we see the need for a method that encourages novices to integrate problem reframing as an essential part of their design process. To conduct our research, we set up a study composed of two parts. The first part focused on the development of a reframing model, based on interviews with expert designers. This was followed by the evaluation of the model, applying an approach composed of workshops and group interviews with novice designers. In this way, our goal was to not only generate a model to support designers in reframing, but also to assess how beneficial it is for design students.

The first part of this study is guided by the following research question: How can we support designers in reframing the problem space to benefit the development of the solution space?

\subsection{Research method - Research question 1}

To investigate the aforementioned research question, we conducted two interviews with expert designers, both with extensive knowledge and experience in the academic and business context. Both have over 25 years of experience in different renowned Dutch design firms and over four years of teaching experience in an international design engineering faculty. In their role of professors of 
practice, they teach design students from both an academic and an industry perspective. They were relevant for our study because they are familiar with reframing, and also know how their businesses incorporate design theories in design practice and industry. Interviews were considered the most appropriate research method, as we wanted to gain a deeper understanding of their knowledge.

All interviews were semi-structured of one hour each, for which we used an interview guide. Questions in these guides were composed following the guidelines by Patton (2002). Several topics were explored, such as how they define problems in their projects, what type of methods support this process, what factors influence the definition of the problem space and what characterises a welldefined problem space. The interviews were conducted in a closed and quiet room to prevent distractions and to improve the quality of audiotape recordings used for transcription.

\subsection{Analysis - Research question 1}

The interviews were completely transcribed verbatim. For the analysis, we used the Grounded Theory Method, as described by Birks \& Mills (2015). We first individually coded a subset of the transcripts. This was done mostly by In Vivo Coding and In Process Coding, as they are two recommended methods by Saldaña (2012a). This ensured that the codes accurately represented the data. Since both researchers were part of the interview, and were able to provide different perspectives, the analysis was carried out jointly. For this research, no inter-rater agreement was calculated. However, we compared and merged our codes and composed a codebook together, after the initial individual round of coding. In this way, we ensured that all transcripts were coded in a similar way. This codebook was used to code the remainder of the transcripts.

We then continued our coding process with focused coding, as described by Saldaña (2012b). We printed all of the initial codes and started clustering them. Fairly quickly, categories, or focused codes, emerged. We then looked into the relationships between different codes, to see the coherent whole, revealing 200 codes that fit into around 15 categories and 7 themes, in total. Some of these themes were 'design tools and processes from practice', 'problem space clarity' and 'project developments over time', just to name a few. Examples of codes are 'looking back at goal', 'way of using models' and 'project step: manifestation'. They are strongly related to the first research question.

\section{RESULTS - RESEARCH QUESTION 1}

The interviews provided us with many insights into the design process of expert designers. What we discovered in our literature review was underpinned and elaborated on. The existence of a problem and solution space and the relationship between them was discussed, and both interviewees observed co-evolution transitions in their practices. This is in line with the views of Maher \& Poon (1996) and Dorst \& Cross (2001). More importantly, three key elements of a design process emerged from the interview analysis of the expert designers: goal, manifestation and methods. These elements were considered crucial to characterise their design processes. Our findings suggest that these three key elements could be beneficial to consider in an updated rendition of the existing co-evolution model (Maher \& Poon, 1996), in relation to framing. Our elaborated framing model is shown in Figure 1.

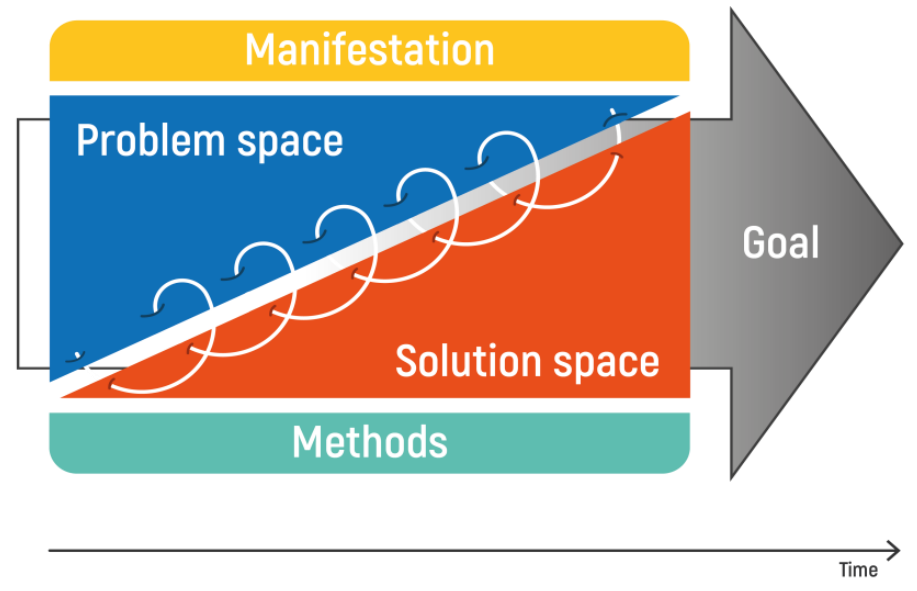

Figure 1. Developed framing model 


\subsection{Explanation of the model}

This model could serve as a guide in the design process to encourage designers to reframe, taking the perspective of the co-evolution of the problem and solution spaces. The model could support awareness of flexible design spaces, acknowledging their existence and importance.

As described earlier, the model is an elaboration on the co-evolution model (e.g., Maher \& Poon, 1996; Dorst \& Cross, 2001), where the problem and solution space co-evolve together through time (represented by the spiral white line that ties up both spaces).

At the beginning of any design project, more time is spent in the problem space. Nevertheless, ideation does not start only when the problem is completely understood. Quite the opposite, it can run in parallel with the problem space framing, as is shown in Figure 1. According to one of our interviewees, "the sooner you start designing [entering the solution space], the sooner you discover the problem". Towards the end of a project, more time is spent in the solution space, but "in practice, they [problem \& solution space] end at the same time", as one interviewee explained. This view coincides with Cross (1997) and Dorst \& Cross (2001), who proposed that co-evolutionary processes finish with the building of a bridge between problem and solution space, i.e., a solution that addresses the reframed problem. This is visualised by the two triangles that start and end at the same time, but change in size over the project course, indicating that more time is spent in the problem space in the beginning, and in the solution space at the end.

Furthermore, our expert interviewees indicated that, to guide this co-evolutionary process, it is very important to have a clear project goal. This is visualised by the arrow that starts before the problem and solution space in Figure 1. One interviewee mentioned: "The consciousness of where you currently are and where you want to go related to your goal, that is very important". The other interviewee shared this vision: "When you are able to define what we actually want at the start of a project [...] you save a lot of time". This is not the same as having a clear problem definition right in the beginning. As previously indicated, the design process is characterised by its fluidity, in which the understanding of what the problem is may change a great deal. A goal refers then to the value the design may bring, which provides direction for the project and may support that all involved in the project are on the same page. This goal is, obviously, not always clear in the beginning but it becomes clearer and more defined over time, making the arrow more opaque towards the end in this model.

Additionally, our interviewees argued that the design process is usually underpinned by many design methods, either employed implicitly or explicitly. One interviewee said: "We [the design agency] have a lot of models and methods and processes". The other interviewee explains why designers need methods: "I use a set of tools, and they are scientifically underpinned, and how you make it [a project] credible". Designers often use a compact number of methods regularly, which have been adapted or refined to fit their preferences (Gonçalves et al., 2014). This sample of methods ensures the credibility of their projects, combined with decisions made on intuition (Daalhuizen, 2014). In the model, this is visualised by the methods bar that is literally underpinning the rest of the model.

Finally, the two interviewees stressed the importance of manifestations, such as any form of externalising one's thoughts in order to enhance explicitness. A design manifestation could then be a conversation, concepts, sketches or prototypes, to trigger transitions within and between the problem and solution spaces. In literature, this concept has been described also as 'externalisation of thought' (e.g., Dix \& Gongora, 2011) or design representations (Goldschmidt, 1997). Both interviewees suggested different examples of manifestations from their practices, such as creating a process storyline or a concept car. One interviewee explained: "It is very important that there continuously is an incredible awareness of where you are [in the process] and what you are doing. We are now working for a big financial client, and we consciously decided to establish a concept car in which we go all out, to wake up everyone within the organisation. [...] We do this consciously to get people to think". The developed concept car was not a feasible solution to the design problem. By "going all out" with futuristic solutions it was merely used to challenge employees' frames of technical possibilities, i.e. broaden their solution space. In this way, manifestation, using a tangible concept to trigger new ideas to implement in real cars, stimulated new co-evolution transitions to or within the solution space. The other interviewee suggested creating a process storyline "to ensure that problem and solution end up in the same place. [...] I know very skilled designers who start creating a process storyline from day one. [...] The day he started a new project, he started creating a Powerpoint, so he knew that at the end of the project, in 30 slides, the story is just right". The interviewee illustrated how manifesting one's process in a tangible or explicit manner, such as through a Powerpoint presentation, helps to discover gaps in the process, encouraging one to further explore the problem space. 
In sum, the model we created is an elaboration of the co-evolution model by Maher \& Poon (1996) and Dorst \& Cross (2001), to which we added three relevant elements, based on interviews with design experts: goal, methods and manifestation. This model aims to support designers in reframing the problem space to benefit the development of the solution space.

\section{SET UP OF THE TWO-PARTS STUDY - PART 2}

To ensure that this model is practically relevant, it was important to test it in an actual design process. To shape this part of the study, a second research question was defined: To what extent does this model benefit the development of the solution space, by supporting reframing the problem space?

\subsection{Research method - Research question 2}

For this second research question, we conducted four group interviews with four groups of two to three students during two workshop sessions. The students were doing their bachelor final project, a design course of ten weeks that signifies the completion of their bachelor studies. While they were still novice designers, they were over halfway in their design education, about to start their Master's.

In the first workshop (which took place three weeks after the start of their design project), we explained the model to an initial group of 21 design students. We then provided them with a printed set of methods that were selected from the Delft Design Guide (van Boeijen et al., 2013) and the Delft Design Tools \& Methods card set from the TU Delft, which both provide a concise overview of design methods (Figure 2). These cards explained each method and its goal, and mostly served as inspiration on how to practically apply the model. After the explanation, there was an opportunity for questions. Students were then encouraged to select a method to explore during the workshop. In addition, students were asked to manifest their thoughts by sharing them with fellow students or sketching ideas and questions. In total, the first workshop took approximately two hours. Subsequently, the students worked on their projects for three more weeks without our supervision. It is important to note that when explaining the model to students we had a different perception of what manifestations meant. We initially called the space 'story', following a quote from the interviewees of Part 1 of this study, where 'story' referred to how ideas were externalised. However, this was confusing for design students, who were thinking in terms of personas and scenarios. Therefore, we later adopted the term manifestation, which better encompasses what our expert interviewees described (as explained in the last two paragraphs of section 4.1).

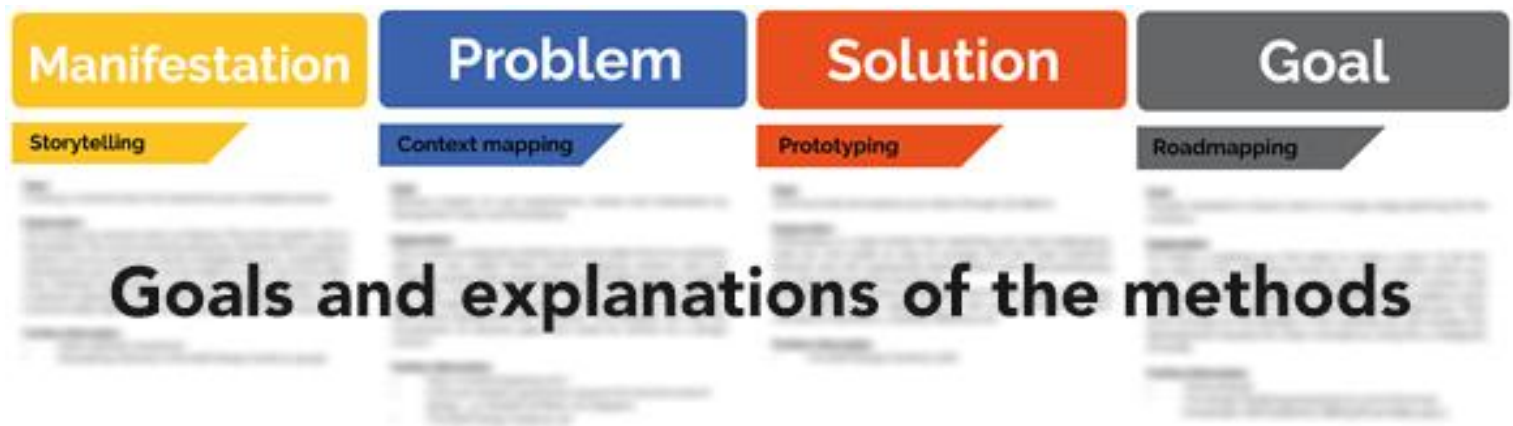

Figure 2. Sample of the provided method cards, which used 'story' instead of 'manifestation'

The second workshop session took place three weeks after the first workshop. We invited the same 21 students again and a smaller sample of the group joined in: nine students, divided over four small groups of two or three students for group interviews, which lasted between thirty minutes to one hour. We chose to conduct group interviews because they provide rich data and allow us to enter into the participants' perspective (Patton, 2002), enabling us to explore their behaviour and reasoning (Stokes \& Bergin, 2006). Since we wanted to investigate how the model impacts the design process, we wanted to acquire a broad dataset, as opposed to an in-depth dataset. Therefore, we conducted interviews with group samples instead of individuals, as suggested by Stokes \& Bergin (2006). As opposed to focus groups, group interviews were preferred because: "In group interviews the interviewer seeks answers, in focus groups the facilitator seeks group interaction" (Bloor et al., 2001, p. 43). As we were not interested in the interaction of the group, but in the broadness of answers they supplied, group interviews were our method of choice.

Additionally, for triangulation purposes, notebooks of students were consulted to investigate whether the students' statements conveyed a change in their process. While reviewing notebooks, we searched 
for mentions of problem, solution, goal, methods and manifestation elements, such as drawings or other notes that communicated if and how the model was applied. Their notebooks, used during the full time of their project, provided us with an authentic and unprocessed depiction of the thought processes of the students, captured as it was created. The notebooks are then appropriate tools to investigate reflective practices (e.g., Oehlberg, Lau \& Agogino, 2009). To avoid observer bias, the procedure related to data collection was carefully analysed in advance by an external researcher (third author), in order to train and prepare for the sessions.

\subsection{Analysis - Research question 2}

This analysis was based on the group interviews, transcribed in verbatim, supported by the students' notebooks. To analyse the interviews, we created an initial coding scheme, by coding one of the four transcripts together. The coding scheme was still flexible, since a coding scheme always evolves until all transcripts are coded (Saldaña, 2009). Using this first version of the coding scheme two of the authors coded individually the same $20 \%$ of the transcriptions and compared them afterwards. Again, no inter-rater agreement was calculated, but initial disagreements were discussed and resolved, ensuring all transcripts were subsequently coded in a similar way. There were no situations where agreement could not be reached. The remaining interviews were coded separately with the revised coding scheme. Examples of codes that were discovered are 'switching spaces', 'model confirms process' and 'iterating in each space over and over'. In addition, themes were discerned, such as 'model application' and 'model impact', which were again considered highly relevant for the study. After all transcripts were coded, we used the 'codeweaving' method, described by Saldaña as "(...) the actual integration of key code words and phrases into narrative form to see how the puzzle pieces fit together." (2009, p. 187). The codes and themes resulted in a number of findings in our study, which are discussed in the following section.

\section{RESULTS - RESEARCH QUESTION 2}

As introduced in section 5, the second research question aimed to investigate to what extent is the model beneficial to support designers in reframing their problem and solution spaces. This study yielded two major insights. One striking result is that, prior to the first workshop, the students perceived the problem space to be completely fixed once they defined it, even if they discovered disparate information along the way. The workshops changed students' mindset on this subject. Participants mentioned that they look differently at their own design process now, as supported in the following quote: "I notice that with this [model] I got a sort of confirmation that it is not that strange to go back to the problem while you are working on solutions". Furthermore, they realised the importance of matching potential solutions against the problem space to identify necessary alterations in the problem definition: "So it is good to indeed continuously go back and forth, and that you test it [the solution] again against your initial problem". The second major insight is that the model provided the students with guidance and confidence in a complex and ambiguous problem, while taking away the one fixed point that they had (their fixed problem definition). However, the way that the model provided guidance to students was diverse. One student explained the way the model provided guardrails in her process: "I wrote down that model, and I tried to summarise in the spaces what I did so that I got a clear view of how it worked together". Four other students mentioned: "[the model encouraged to] record my process. [...] That provided structure". Three others said: "It [the model] ensured consciousness, not structure". In this case, rather than precise steps, the participants were able to take from the model awareness, which provided moments to reflect on their design process.

Five out of nine students expressed that gaining the freedom to adjust the problem space, and learning about this model, helped them to become more confident in their process: "Seeing the model gave me a kind of confidence". Another student also said: "Before [the model] I found it too risky to switch between them [problem and solution space], but now I would do that". Based on their own perception, all design students were confident that they spent more time reframing the problem space after seeing the model than before seeing the model.

Figure 3 shows one of the student's notebooks, which illustrates the findings from the group interviews. The notebook showed that she started planning her presentations in the notebook, an approach that one of our expert interviewees suggested as a form of manifestation, which we advised to her during the workshop. In Figure 3, it is clear that she later added different types of information to her presentation, showing iterations of the presentation, and further exploration of how to represent the problem space. 


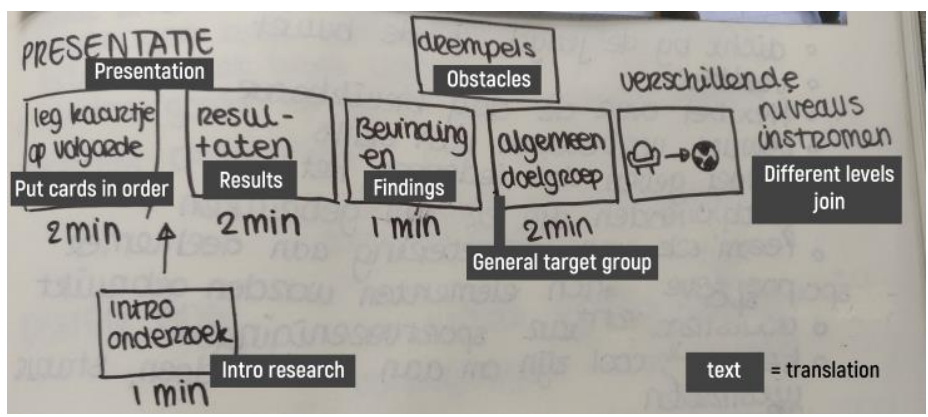

Figure 3. Notebook page of one of the design students

To answer our second research question, this model had a considerable self-reported impact on the student's design processes. Two major findings were that students perceived the problem space to be fixed and that removing this fixed point but adding guardrails provided students with guidance and a sense of confidence. They mentioned that, based on their own perception, they made more transitions between the solution and problem space more often than before the model. The extra attention to the problem space self-reportedly led them to reframe the problem more often. Therefore, we can suggest that the model offers support to design students in reframing the problem space. Ultimately, reframing the problem space tends to lead to more solution opportunities and ideas in the solution space, as indicated by Dorst \& Cross (2001). Thus, by aiding reframing, this model can also benefit the development of the solution space.

\section{DIscussion}

Based on the feedback we received during our group interviews, as well as feedback from fellow designers, we iterated on the model and created a refined version (Figure 4). This revision aims to better represent the new elements and how they add to the co-evolution model in relation to framing.

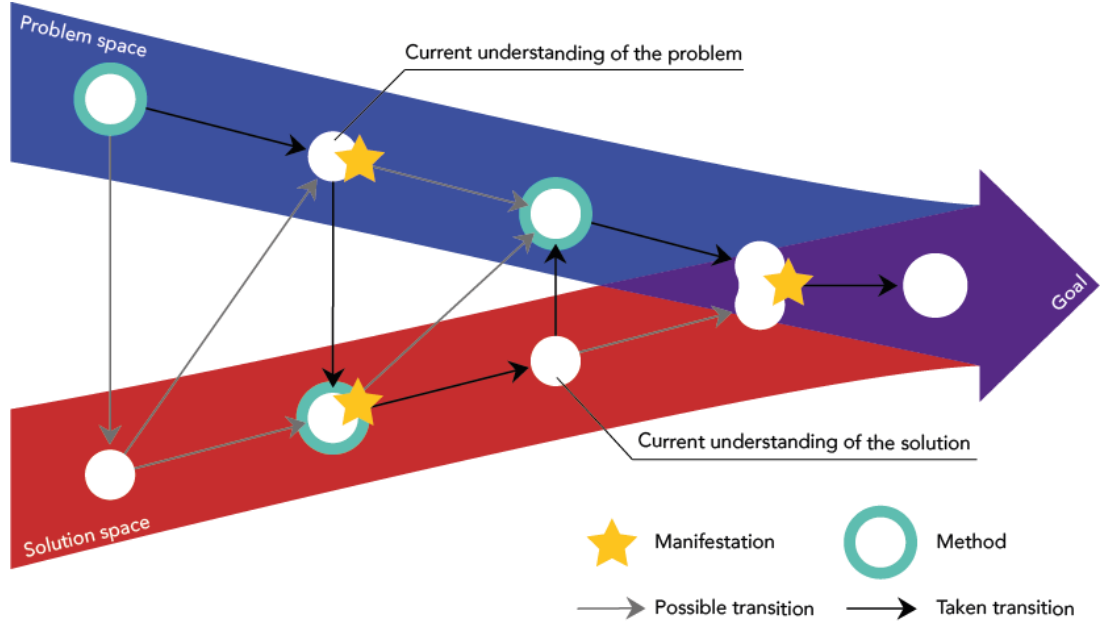

Figure 4. Refined model of framing

This revision shows how the different elements of the model work together through co-evolution transitions between the problem and solution space. The model is greatly simplified for clarity purposes. The suggested transitions (arrows in black) are just one of many examples of how a design process could develop; other possible transitions are indicated by the grey arrows. In the refined model, it is clear that the problem and solution space start simultaneously but as two separate entities, influencing each other. Through co-evolution transitions between and within the spaces, they are brought closer together until they overlap and match when a solution successfully answers an (interpretation of the) problem. The goal is represented by the direction of the model, the purple arrow at the far right. As explained in section 4.1, the goal is the value that the design process could bring, and where the problem and solution space meet. Manifestation and method are not represented as spaces anymore, but as elements that can support the solution or problem space and aid a transition to one or the other. The depiction of these elements is more representative of how they work in practice. As illustrated by the model, transitions are not always triggered by manifestations, or not always supported by methods. At different moments of the design process, certain manifestations and methods become crucial, supporting transitions. It is important to 
reinforce that the indication of method and manifestation in Figure 4 are only suggestions, as a possible simulation of a design process. Every design process is unique and hence the circumstances where methods and manifestations take place might vary.

This research demonstrated that providing design students with a model that supports their design process stimulated them to frequently reframe their problem space, leading towards more solution opportunities. This was mostly due to increased process awareness and perceived guardrails. This underpins the findings of Dorst \& Cross (2001) regarding co-evolution.

The spaces that were added to the original co-evolution model, manifestation, goal and methods, helped design students in covering important aspects of the design process. This model can be viewed as an elaboration on the co-evolution model by Maher \& Poon (1996), aimed to support framing.

Our findings, particularly regarding manifestation and methods, support past literature on framing and reframing. Stompff et al. (2016) have revealed the importance of surprises as incentives to reframing, to which Cash \& Goncalves (2017) elaborated to include knowledge and information sharing. To these studies, we are able to add that methods and design manifestations (such as sketches or powerpoint presentations) also support the transitions between and within spaces.

\section{CONCLUSIONS}

This article has developed and tested a framing model based on co-evolution transitions, through a two-parts study: interviews with expert designers and workshops followed by group interviews with novices. The resulting model offers a way of thinking and a way of working, based on the fluidity of the design process and on transitions between spaces supported by goal, methods and manifestations. At this point, it is important to consider some limitations of this study. Firstly, in our approach to validate the model, we only considered individual designers, in this case, design students in an individual Bachelor End project. While this enabled us to more easily translate from the current co-evolution model (Dorst \& Cross, 2001), who also used individual designers, future research could validate these results with expert designers, also working in teams.

Regarding the second part of the study, the students' perception of the model was mostly based on how the model was explained to them. At the time, they were presented with a first version of the model. Over time, our thinking process and thus the model co-evolved, just as any design process does. Currently, we would explain the model differently (e.g. using Figure 4, not Figure 1) than we did during the first workshop, supported by our final findings. Future work needs to be done in order to investigate how the refined version of the model (Figure 4) could support novices in their design processes.

This study based the results of time spent reframing on students' own perceptions and their notebooks. An opportunity for further research lies in adopting other ways of investigating this aspect.

Furthermore, we conducted group interviews instead of individual interviews, due to time constraints. Bloor et al. (2001, p. 42) note: "Group interviews are rarely to be preferred to individual interviews in academic social research as individual differences in viewpoint within the group will be blurred and underreported". In group interviews, it is important that the interviewer is able to work with different personalities, making sure that no one dominates the group interview and that everybody's views and opinions are expressed (Widdows et al., 1991). Both interviewers had experience in leading and moderating group conversations and ensured that everyone was able to express their opinions by specifically asking participants to elaborate when necessary.

As indicated in section 5.1, the model was complemented by a set of methods to support the students in the application of the model in their design processes. Evaluating the influence of the tools in relation to the model was outside of the scope of the paper. Nevertheless, to increase the applicability of the model in design education, future research should investigate the combination of methods and model to support framing. Furthermore, we recommend extending the model by adding examples and a more elaborate guide on how to use it. Currently the model is rather descriptive, and participants have mentioned that they would have liked to be able to refer back to an explanation of each space, and preferably concrete examples of how to apply it. This is, again, an opportunity for future research.

The model was developed to support designers in framing, independently of their expertise level, during creative processes. Nevertheless, the findings of this study can be particularly useful for design education. It is important to reinforce to our design students that both the problem and solution understanding are fluid. The problem and solution spaces co-evolve, by setting goals, underpinned by methods and manifestations. Ultimately, this model takes initial steps to help designers in structuring their process, providing confidence into exploring both the problem and solution spaces. 


\section{REFERENCES}

Akin, Ö. and Akin, C. (1996), "Frames of reference in architectural design: analysing the hyperacclamation (A-h-a!)". Design Studies, Vol. 17 No. 4, pp. 341-361.

Almendra, R., and Christiaans, H. (2011), "Design students' perception of their own design process". 4th World congress on design research, Proceedings of the IASDR 2011, Delft, 2011, N. Roozenburg, L. L. Chen, and P. J. Stappers (Eds.), Delft.

Benammar, K. (2012), Reframing: The art of thinking differently. Boom uitgevers Amsterdam.

Birks, M. and Mills, J. (2015), Essentials of grounded theory. Grounded theory: A practical guide (2nd ed., pp 1-15). SAGE, London.

Bloor, M., Frankland, J., Thomas, M. and Robson, K. (2001), Focus groups in social research. SAGE, London.

Cash, P., and Gonçalves, M. (2017), "Information-triggered Co-evolution: A Combined Process Perspective". In Christensen, B. T., Ball, L. J. and Halskov, K. (Eds.), Analysing Design Thinking: Studies of Cross-Cultural CoCreation (pp. 501-520). CRC Press

Christiaans, H. (1992), “Creativity in design”. PhD Thesis, Delft University of Technology, Delft, The Netherlands

Cross, N. (1997), "Descriptive models of creative design: application to an example”, Design Studies, Vol. 18 No. 4, pp. $427-455$.

Cross, N. (2004), "Expertise in design: an overview”. Design Studies, Vol. 25 No. 5, pp. (427-441).

Daalhuizen, J. J. (2014), “Method Usage in Design: How methods function as mental tools for designers.” PhD Thesis, Delft University of Technology, Delft, The Netherlands.

Dix, A., and Gongora, L. (2011), "Externalisation and Design", Proceedings of the Second Conference on Creativity and Innovation in Design, New York, NY, USA: ACM, (pp. 31-42).

Dorst, K. and N. Cross (2001), "Creativity in the design process: co-evolution of problem-solution.” Design studies, Vol. 22 No. 5, pp. 425-437.

Dorst, K. (2011), "The core of 'design thinking' and its application”. Design studies, Vol. 32 No. 6, pp. 521-532.

Dorst, K. (2015), Frame innovation: Create new thinking by design. MIT Press.

Goldschmidt, G. (1997), "Capturing indeterminism: representation in the design problem space". Design Studies, Vol. 18 No. 4, pp. 441-455.

Gonçalves, M., Cardoso, C., and Badke-Schaub, P. (2014), "What inspires designers? Preferences on inspirational approaches during idea generation". Design Studies, Vol. 35 No. 1, pp. 29-53.

Guest, G., Bunce, A., and Johnson, L. (2006), "How many interviews are enough? An experiment with data saturation and variability”. Field Methods, Vol. 18 No. 1, pp. 24.

Hey, J. H., C. K. Joyce and S. L. Beckman (2007), "Framing innovation: negotiating shared frames during early design phases.” Journal of Design Research, Vol. 6 No. 1-2, pp. 79-99.

Kim, J. and Ryu, H. (2014), “A Design Thinking Rationality Framework: Framing and Solving Design Problems in Early Concept Generation”, Human-Computer Interaction, Vol. 29 No. 5-6, pp. 516-553.

Maher, M. L. and J. Poon (1996), "Modeling design exploration as co-evolution." Computer-Aided Civil and Infrastructure Engineering, Vol. 11 No. 3, pp. 195-209.

Patton, M. Q. (2002), “Qualitative interviewing”. Qualitative research \& evaluation 54 methods (3rd ed., pp. 339-418). SAGE, Thousand Oaks, CA.

Oehlberg, L., Lau, K. and Agogino, A. (2009), "Tangible interactions in a digital age: Medium and graphic visualization in design journals". Artificial Intelligence for Engineering Design, Analysis and Manufacturing, Vol. 23, pp. $237-249$.

Saldaña, J. (2009), The coding manual for qualitative researchers. SAGE, London.

Saldaña, J. (2012a). First cycle coding methods. The coding manual for qualitative researchers (2nd ed., pp. 58-186). SAGE, London.

Saldaña, J. (2012b). Second cycle coding methods. The coding manual for qualitative researchers (2nd ed., pp. 207-245). SAGE, London.

Saunders, M.N. (2007), Research methods for business students, 5/e. Pearson Education India.

Schön, D. (1983), The reflective practitioner: How professionals think in action. Basic Books, New York.

Schön, D. (1988), "Designing: Rules, types and worlds”. Design Studies, Vol. 9, pp. 181-190.

Stokes, D., and Bergin, R. (2006), "Methodology or "methodolatry"? An evaluation of focus groups and depth interviews". Qualitative market research: An international Journal, Vol. 9 No. 1, pp. $26-37$.

Stompff, G., F. Smulders and L. Henze (2016), "Surprises are the benefits: reframing in multidisciplinary design teams." Design Studies, Vol. 47, pp. 187-214.

Suppes, P. (1960), "A Comparison of the Meaning and Uses of Models in Mathematics and the Empirical Sciences", Synthèse, Vol. 12, 287-301.

Van Boeijen, A., Daalhuizen, J., Zijlstra, J., and Van der Schoor, R. (2013), The Delft Design Guide. BIS, Amsterdam, The Netherlands.

Widdows, R., Hensler, T. A., and Wyncott, M. H. (1991), The focus group interview: a method for assessing users' evaluation of library service.

Wiltschnig, S., B. T. Christensen and L. J. Ball (2013), "Collaborative problem-solution co-evolution in creative design." Design Studies, Vol. 34 No. 5, pp. 515-542. 